\title{
Risk of Hyperkalemia in Nondiabetic Patients With Chronic Kidney Disease Receiving Antihypertensive Therapy
}

\author{
Joy M. Weinberg, MD, Lawrence J. Appel, MD, MPH, George Bakris, MD, Jennifer J. \\ Gassman, PhD, Tom Greene, PhD, Cynthia A. Kendrick, BS, Xuelei Wang, MS, James Lash, \\ MD, Julia A. Lewis, MD, Velvie Pogue, MD, Denyse Thornley-Brown, MD, Robert A. Phillips, \\ MD, PhD, and African American Study of Hypertension and Kidney Disease Collaborative \\ Research Group
}

\section{(C2009 American Medical Association. All rights reserved}

Correspondence: Robert A. Phillips, MD, PhD, Heart and Vascular Center of Excellence, UMASS Memorial Medical Center, 55 Lake Ave N, Room S3-836, Worcester, MA 01655 (robert.phillips@umassmemorial.org)..

African American Study of Hypertension and Kidney Disease Collaborative Research Group

Case Western Reserve University—Principal Investigators: J. Wright, R. Haynie, C. Mbanefo, M. Rahman, M. Smith, B. Crenshaw, and R. Dancie; Study Coordinators: Y. Hall and L. Jaen; Emory University—Principal Investigators: W. D. Hall, T. Olutade, and J. Lea; Study Coordinators: M. Douglas, A. Chapman, B. Wilkening, J. Carlone, D. Watkins, L. Dean, and L. Williams; Harbor-UCLA Medical Center-Principal Investigator: J. Kopple; Study Coordinators: L. Miladinovich, J. Choi, and P. Oleskie; Harlem Hospital Center-Principal Investigators: V. Pogue, H. Anderson, L. Herbert, and J. Cheng; Study Coordinators: D. Dowie, B. Nicholas, G. Darkwa, and V. Dowdy; Howard University—Principal Investigators: O. Randall, and T. Retta; Study Coordinators: S. Xu, M. Ketete, and D. Ordor; Johns Hopkins University—Principal Investigator: L. Appel; Study Coordinators: J. Charleston, C. Diggs, C. Harris, E. Miller, T. Shields, M. Sotomayer, and P. Whelton; Martin Luther King, Sr/Charles R. Drew Medical Center—Principal Investigators: K. Norris, H. Ward, and D. Martins; Study Coordinators: M. Miller and H. Howell; Medical University of South Carolina-Principal Investigators: D. Cheek, C. Gadegbeku, and D. Ploth; Study Coordinators: D. Brooks, V. Brown, N. Monestime, S. Thompson, L. Brown, and S. Murner; Meharry Medical College—Principal Investigators: M. Faulkner and O. Adeyele; Study Coordinators: K. Phillips, G. Sanford, and C. Weaver; Morehouse School of Medicine-Principal Investigators: W. Cleveland, A. Howard, K. Chapman, and S. Plater; Study Coordinator: W. Smith; Mount Sinai School of Medicine_Principal Investigators: R. Phillips and M. Lipkowitz; Study Coordinators: A. Gabriel, A. Travis, and J. Williams; Ohio State University—Principal Investigators: L. Hebert, S. Ladson-Wofford, N. Nahman, and K. Osei; Study Coordinators: L. Hiremath, A. Dodley, J. Parks, and D. Veley; Rush PresbyterianSt Luke's Medical Center-Principal Investigators: G. Bakris and J. Lash; Study Coordinators: L. Fondren, L. Bagnuolo, J. Cohan, M. Powell, A. Smith Folker, D. White, G. Henry, A. Johnson, T. Collins, S. Koshy, E. Afante, and L. Kennedy Dixon; University of Alabama, Birmingham-Principal Investigators: S. Rostand and D. Thornley-Brown; Study Coordinator: B. Key; University of California, San Diego-Principal Investigators: D. T. O'Connor, F. B. Gabbai, and F. Rao; Study Coordinator: J. Mount; University of Florida—Principal Investigator: C. C. Tisher; Study Coordinators: L. Burgin, C. Sarmiento, A. Diaz, and D. Allen; University of Miami-Principal Investigators: J. Bourgoignie, G. Contreras, and D. Florence-Green; Study Coordinators: A. Doss, J. Junco, D. Merrill, J. Vassallo, and A. de Velasco; University of Michigan—Principal Investigators: K. Jamerson, F. Port, M. Keshishian, A. Ojo, and S. Steigerwalt; Study Coordinators: D. Cornish-Zirker, T. Graham, A. Johnson, J. Layne, S. Nesbitt, K. Manchester, and W. Bloembergen; University of Southern California-Principal Investigators: S. Massry, V. Campese, and M. Smogorzewski; Study Coordinator: A. Richardson; University of Texas Southwestern Medical Center, Dallas-Principal Investigators: R. Toto, S. Leach, E. Kuo, and H. Mitchell; Study Coordinators: T. Lightfoot and S. A. Blackstone; Vanderbilt University—Principal Investigators: J. Lewis and G. Schulman; Study Coordinators: N. Rogers, M. Sika, and S. McLeroy; National Institute of Diabetes and Digestive and Kidney Diseases_L. Y. Agodoa, J. P. Briggs, and J. W. Kusek; Steering Committee Chair-J. Douglas; Data Coordinating Center (Cleveland Clinic Foundation)—J. Gassman, G. Beck, V. Dennis, T. Greene, and M. Kutner; Study Coordinators: K. Brittain, S. Sherer, R. Stewart, L. Tuason, S.-R. Wang, X. Wang, and W. Zhang; Central Biochemistry Laboratory-F. Van Lente, J. Waletzky, C. O. Laughlin, C. Peck, and J. Susa; Central GFR Laboratory—P. Hall, D. Pexa, and H. Rolin; Blood Pressure Consultant-R. Byington; Psychological Consultant-P. Greene; External Advisory Committee-R. Luke, V. Chin-chilli, C. Cook, B. Falkner, C. Ford, R. Glassock, T. Karrison, T. Kotchen, E. Saunders, M. Secundy, and D. Wesson

Author Contributions: Study concept and design: Weinberg, Appel, Bakris, Gassman, Thornley-Brown, and Phillips. Acquisition of data: Appel, Bakris, Gassman, Wang, Lewis, Pogue, Thornley-Brown, and Phillips. Analysis and interpretation of data: Weinberg, Appel, Gassman, Greene, Kendrick, Wang, Lash, Lewis, Pogue, Thornley-Brown, and Phillips. Drafting of the manuscript: Weinberg, Kendrick, Wang, and Phillips. Critical revision of the manuscript for important intellectual content: Weinberg, Appel, Bakris, Gassman, Greene, Kendrick, Lash, Lewis, Pogue, and Thornley-Brown. Statistical analysis: Gassman, Greene, Kendrick, Wang, and Phillips. Obtained funding: Appel, Bakris, Lash, and Phillips. Administrative, technical, and material support: Weinberg, Appel, Gassman, Pogue, and Phillips. Study supervision: Appel, Lewis, Pogue, and Phillips.

Financial Disclosure: None reported.

Previous Presentation: This study was presented as a poster at the American Heart Association's 63rd High Blood Pressure Research Conference; September 23, 2009; Chicago, Illinois. 
Nephrology Division, Lenox Hill Hospital, New York, New York (Dr Weinberg); Welch Center for Prevention, Epidemiology, and Clinical Research, Johns Hopkins University, Baltimore, Maryland (Dr Appel); Hypertensive Diseases Unit, Department of Medicine, University of Chicago Pritzker School of Medicine, Chicago, Illinois (Dr Bakris); Department of Biostatistics and Epidemiology, The Cleveland Clinic Foundation, Cleveland, Ohio (Drs Gassman and Greene and Mss Kendrick and Wang); Section of Nephrology, University of Illinois, Chicago (Dr Lash); Division of Nephrology, Vanderbilt University, Nashville, Tennessee (Dr Lewis); Division of Nephrology, Harlem Hospital, New York (Dr Pogue); Division of Nephrology, University of Alabama at Birmingham, Birmingham (Dr Thornley-Brown); and Heart and Vascular Center of Excellence, UMass Medical School and UMass Memorial Medical Center, Worcester, Massachusetts (Dr Phillips)

\section{Abstract}

Background-The incidence and factors associated with hyperkalemia in patients with chronic kidney disease (CKD) treated with angiotensin converting enzyme inhibitors (ACEIs) and other antihypertensive drugs was investigated using the African American Study of Kidney Disease and Hypertension (AASK) database.

Methods-A total of 1094 nondiabetic adults with hypertensive CKD (glomerular filtration rate [GFR], 20-65 mL/min/1.73 $\mathrm{m}^{2}$ ) were followed for 3.0 to 6.4 years in the AASK trial. Participants were randomly assigned to ACEI, $\beta$-blocker (BB), or dihydropyridine calcium channel blocker (CCB). The outcome variables for this analysis were a serum potassium level higher than 5.5 $\mathrm{mEq} / \mathrm{L}$ (to convert to millimoles per liter, multiply by 1.0 ), or a clinical center initiated hyperkalemia stop point.

Results-A total of 6497 potassium measurements were obtained, and 80 events in 51 subjects were identified ( 76 events driven by a central laboratory result and 4 driven by a clinical centerinitiated hyperkalemia stop point). Compared with a GFR higher than $50 \mathrm{~mL} / \mathrm{min} / 1.73 \mathrm{~m}^{2}$, after multivariable adjustment, the hazard ratio (HR) for hyperkalemia in patients with a GFR between 31 and $40 \mathrm{~mL} / \mathrm{min} / 1.73 \mathrm{~m}^{2}$ and a GFR lower than $30 \mathrm{~mL} / \mathrm{min} / 1.73 \mathrm{~m}^{2}$ was $3.61(95 \%$ confidence interval [CI], 1.42-9.18 [ $P=.007])$ and 6.81 (95\% CI, 2.67-17.35 [ $P<.001])$, respectively; there was no increased risk of hyperkalemia if GFR was 41 to $50 \mathrm{~mL} / \mathrm{min} / 1.73 \mathrm{~m}^{2}$. Use of ACEIs was associated with more episodes of hyperkalemia compared with CCB use (HR, 7.00; 95\% CI, 2.29$21.39[P<.001])$ and BB group (HR, 2.85; 95\% CI, 1.50-5.42 [ $P=.001])$. Diuretic use was associated with a $59 \%$ decreased risk of hyperkalemia.

Conclusions-In nondiabetic patients with hypertensive CKD treated with ACEIs, the risk of hyperkalemia is small, particularly if baseline and follow-up GFR is higher than $40 \mathrm{~mL} / \mathrm{min} / 1.73$ $\mathrm{m}^{2}$. Including a diuretic in the regimen may markedly reduce risk of hyperkalemia.

SeVERal studies have demonstrated that angiotensin-converting enzyme inhibitors (ACEIs) blunt progression of renal disease in nondiabetic patients with chronic kidney disease (CKD). ${ }^{1-4}$ However, ACEIs can cause hyperkalemia by impairing renal potassium excretion through interference with production and/or secretion of aldosterone. ${ }^{5}$ Hyperkalemia from ACEI use has been frequently described, ${ }^{6-8}$ and ACEIs are often underprescribed in patients with CKD because of concerns of hyperkalemia. ${ }^{9} \beta$-Blocker (BB) use has also been associated with hyperkalemia, most likely through redistribution of potassium from intracellular to extracellular compartments as a result of blockade of $\beta_{2}$-adrenoreceptor-mediated cellular potassium uptake. ${ }^{10,11}$

The African American Study of Kidney Disease and Hypertension (AASK) was a randomized clinical trial in nondiabetic African Americans with hypertensive CKD. One primary goal was to determine the effects of 3 different classes of antihypertensive agents on progression of renal disease: a dihydropyridine calcium channel blocker (CCB), a BB, and 
an ACEI. The most beneficial drug therapy was with ACEIs. ${ }^{12}$ The other primary goal was to determine the effects of 2 different BP goals on progression of renal disease; the trial demonstrated that a target mean arterial BP (MAP) of 102 to $107 \mathrm{~mm} \mathrm{Hg}$ was as effective as stricter BP goal of a MAP lower than $92 \mathrm{~mm} \mathrm{Hg} .{ }^{12}$ Participants had a glomerular filtration rate (GFR) between 20 and $65 \mathrm{~mL} / \mathrm{min} / 1.73 \mathrm{~m}^{2}$ and no identified causes of renal insufficiency other than hypertension. After the close of the trial phase of the AASK, the investigators were directed by the National Institute of Diabetes and Digestive and Kidney Diseases (NIDDK) appointed Data Safety Monitoring Board to use the AASK database to explore factors associated with development of hyperkalemia. In this report, we describe the incidence of hyperkalemia by class of antihypertensive drug in the AASK and report the independent associations of other clinically measured factors

\section{METHODS TRIAL DESIGN}

The design of the AASK study, including complete eligibility and exclusion criteria, has been described elsewhere. ${ }^{12}$ The AASK was a 21 -center, NIDDK-sponsored study that randomized 1094 patients. In a $3 \times 2$ factorial design, patients were randomized to initial treatment with either a BB (metoprolol succinate extended release, 50-200 mg/d), an ACEI (ramipril, 2.5-10.0 mg/d), or a CCB (amlodipine besylate, 5-10 mg/d) and to $1 \mathrm{of} 2 \mathrm{MAP}$ BP goals (102-107 mm Hg or $>92 \mathrm{~mm} \mathrm{Hg}$ ). Initial drug therapy was double blinded.

Participants were African Americans, aged 18 to 70 years, with hypertensive CKD as defined by a diastolic BP higher than $95 \mathrm{~mm} \mathrm{Hg}$ and a glomerular filtration rate (GFR) between 20 and $65 \mathrm{~mL} / \mathrm{min} / 1.73 \mathrm{~m}^{2}$, measured by ${ }^{125}$ I-iothalamate clearance; investigators were blinded to each patient's specific GFR within this range. Individuals were excluded if there was an apparent cause for CKD other than hypertension. Specific exclusion criteria were (1) fasting glucose level higher than $140 \mathrm{mg} / \mathrm{dL}$ (to convert to millimoles per liter, multiply by 0.0555 ), random glucose level higher than $200 \mathrm{mg} / \mathrm{dL}$, or drug therapy for diabetes; (2) urinary protein to urinary creatinine ratio (UP/Cr) higher than 2.5; (3) accelerated or malignant hypertension; (4) secondary hypertension; (5) serious systemic disease; (6) congestive heart failure; (7) specific indication for, or contraindication to, a study drug or procedure; (8) intake of nonsteroidal anti-inflammatory agents (NSAIDs) more than $15 \mathrm{~d} / \mathrm{mo}$, except for aspirin, or inability to discontinue NSAIDs or aspirin for 5 days prior to GFR measurement; and (9) locally measured potassium level higher than 5.5 $\mathrm{mEq} / \mathrm{L}$ during screening.

Each individual institutional review board of the participating institutions approved the study protocol, and written informed consent was obtained for all subjects before enrollment in the trial.

\section{VARIABLE DEFINITIONS}

Hyperkalemia was defined as the occurrence of a centrally measured (Cleveland Clinic Foundation, Cleveland, Ohio) potassium concentration higher than $5.5 \mathrm{mEq} / \mathrm{L}$ at one of the follow-up visits (at months 3, 6, and 12 and at 6-month intervals thereafter throughout the follow-up period until the patient's final serum potassium measurement prior to death) or a clinical center-initiated, hyperkalemia-related stop point. Patients were followed up until the occurrence of end-stage renal disease (ESRD) or, if taking a CCB, until September 22, 2000, when the CCB arm was terminated during trial. ${ }^{12,13}$ Baseline factors evaluated for association with the first episode of hyperkalemia included age, sex, weight, body mass index (BMI) (calculated as weight in kilograms divided by height in meters squared), systolic BP, diastolic BP, MAP, GFR, creatinine level, UP/Cr, randomized drug, baseline 
NSAID use, baseline serum glucose level, and baseline potassium level. Body mass index values were grouped into the following categories: 25 or lower, higher than 25 to 30 or lower, and higher than 30 . Because earlier studies ${ }^{14-16}$ reported increased incidence of elevated potassium level in subject with a GFR below $30 \mathrm{~mL} / \mathrm{min} / 1.73 \mathrm{~m}^{2}$, we evaluated risk using the following GFR categories: $30 \mathrm{~mL} / \mathrm{min} / 1.73 \mathrm{~m}^{2}$ or lower, higher than 30 to 40 $\mathrm{mL} / \mathrm{min} / 1.73 \mathrm{~m}^{2}$ or lower, higher than 40 to $50 \mathrm{~mL} / \mathrm{min} / 1.73 \mathrm{~m}^{2}$ or lower, and higher than $50 \mathrm{~mL} / \mathrm{min} / 1.73 \mathrm{~m}^{2}$.

\section{STATISTICAL ANALYSES}

Baseline characteristics were summarized by standard descriptive statistics (means and standard deviations or frequencies and percentages, as appropriate). Event rates for hyperkalemia events, defined as the first occurrence of a follow-up serum potassium measurement higher than $5.5 \mathrm{mEq} / \mathrm{L}$ or a clinical center-initiated, hyperkalemia-related stop point, were computed as the ratio of the number of events to the total patient-years of follow-up and expressed as the number of events per 100 patient-years. Exact $95 \%$ confidence intervals (CIs) for event rates were calculated based on the Poisson distribution. The association between hyperkalemia and randomized treatment group was assessed by using a discrete-time proportional hazards regression model with a complimentary log-log link function to relate the probability of first occurrence of hyperkalemia at a follow-up visit with a serum potassium measurement to the randomized treatment assignment. ${ }^{17}$ Discretetime proportional hazards regression is analogous to proportional hazards Cox regression in continuous time but accounts for the fact that hyperkalemia could only be observed at visits with a serum potassium measurement. Additional discrete-time proportional hazards models were used to relate the hazard of hyperkalemia to the individual baseline risk factors designated in the previous subsection, controlling only for randomized treatment assignment, and to jointly relate the hazard for hyperkalemia to each of the baseline risk factors and randomized treatment assignment in a multivariable analysis. To determine if the effects of the randomized treatment assignments differed by baseline GFR or BMI levels, interaction tests were performed between randomized groups and baseline GFR and BMI, respectively, treating both baseline factors as continuous variables. Finally, a timedependent discrete time proportional hazards regression was performed to jointly relate the probability of hyperkalemia to a patient's most recent potassium measurement, diuretic use, GFR, and UP/Cr, controlling for randomized groups and baseline age, sex, NSAID use, BMI, and glucose level. Follow-up for the discrete-time proportional hazards regressions and for computation of event rates was censored in all analyses at the time of a patient's final serum potassium measurement prior to the September 22, 2000, when the CCB arm was terminated, ${ }^{13}$ death, or the occurrence of ESRD. Similar analysis was performed to relate the probability of hyperkalemia to a patient's most recent recorded dose of the study-supplied ACEI $(2.5 \mathrm{mg} / \mathrm{d}, 5 \mathrm{mg} / \mathrm{d}$, or $10 \mathrm{mg} / \mathrm{d})$ and BB $(50 \mathrm{mg} / \mathrm{d}, 100 \mathrm{mg} / \mathrm{d}$, or $200 \mathrm{mg} / \mathrm{d})$, with the CCB group serving as the reference and controlling for the same baseline risk factors.

All statistical analyses were performed using SAS version 9.1 (SAS Institute Inc, Cary, North Carolina). Two-sided $P$ values $<.05$ were considered statistically significant, without adjustment for multiple comparisons.

\section{RESULTS}

The baseline characteristics are presented in Table 1. Subjects were predominantly male and on average middle-aged and obese. There was a wide range of systolic BP with a mean of $150.0 \mathrm{~mm} \mathrm{Hg}$. The mean GFR was $46.6 \mathrm{~mL} / \mathrm{min} / 1.73 \mathrm{~m}^{2}$, corresponding to stage 3 chronic kidney disease. The mean (SD) number of potassium measurements was 6.2 (2.6) per patient over a mean follow-up period of 3.0 years. Of the 6497 available pre-ESRD potassium measurements obtained, only 76 met criteria for hyperkalemia (1.2\%). After accounting for 
4 hyperkalemia stop points triggered by a decision at the local center, 76 events driven by a result at the central laboratory were identified, for a total of 80 hyperkalemic events in 51 patients (Table 2). As given in Table 2, $11.2 \%$ of patients with a baseline GFR of $40 \mathrm{~mL}$ / $\mathrm{min} / 1.73 \mathrm{~m}^{2}$ or lower experienced a hyperkalemic event, whereas less than $1.6 \%$ of patients with a GFR higher than $40 \mathrm{~mL} / \mathrm{min} / 1.73 \mathrm{~m}^{2}$ had a hyperkalemic event. As given in Table 3 , the relatively higher rate of hyperkalemia in those with GFR of $40 \mathrm{~mL} / \mathrm{min} / 1.73 \mathrm{~m}^{2}$ or lower persisted in the multivariable analysis, which included adjustment for randomized drug assignment, age at randomization, sex, baseline NSAID use, baseline BMI, baseline UP/Cr, baseline glucose level, and baseline potassium level. There was no significant difference in the rate of hyperkalemia in those with a GFR between 40 and $50 \mathrm{~mL} / \mathrm{min} / 1.73 \mathrm{~m}^{2}$ vs a GFR higher than $50 \mathrm{~mL} / \mathrm{min} / 1.73 \mathrm{~m}^{2}$.

As given in Table 3, without covariate adjustment, assignment to the ACEI group was associated with a hazard ratio (HR) of 3.84 (95\% CI, 1.35-10.89) compared with the CCB group $(P=.01)$ and with an HR of 1.85 (95\% CI, 1.02-3.36) compared with the BB group $(P=.04)$. Hazard ratios comparing the ACEI group with the other drug groups increased in magnitude after adjustment for the baseline factors listed in Table 3. The HR for the BB vs CCB comparison was 2.45 (95\% CI, 0.79-7.65) after adjustment for the baseline covariates but did not attain statistical significance $(P=.12)$. There were no significant differences in the rate of hyperkalemia between dose levels of ACEI, although the power to detect a difference, if it existed, was low because subjects randomized to ACEI were taking $10 \mathrm{mg} / \mathrm{d}$ on at least $68.8 \%$ (range, $68.8 \%-76.3 \%$ ) of their visits during the trial. There was no significant difference in rate of hyperkalemia according to randomization to low vs usual BP goal (Table 3).

Figure 1 displays the rates and 95\% CIs of first occurrences of hyperkalemic events by assigned randomized drug plotted against varying levels of GFR. The figure demonstrates that there was a negligible risk for a hyperkalemic event in each drug group if the baseline GFR was higher than $40 \mathrm{~mL} / \mathrm{min} / 1.73 \mathrm{~m}^{2}$.

Body mass index was independently associated with hyperkalemia. A total of $9.8 \%$ of patients whose BMI at baseline was 25 or lower experienced hyperkalemic events compared with $3.6 \%$ of patients with a baseline BMI higher than 25 . The lower BMI category was associated with an increased hazard for hyperkalemia compared with 25 to 30 BMI group in both univariate and multivariable analyses (Table 3). Figure 2 displays the rates of hyperkalemic events by randomized drug assignment plotted against varying levels of BMI. Especially notable is the relatively greater rate of hyperkalemia in subjects with low BMI who were assigned to either the ACEI or BB groups. Figure 3 presents the rates of hyperkalemic events by BMI category plotted against GFR category. As shown, subjects in the lowest BMI and GFR categories had the greatest risk for a hyperkalemic event.

In univariate analysis, higher baseline levels of the UP/Cr were associated with increased risk of hyperkalemic events throughout the range of this variable (Table 3). However, in multivariable analysis, only those subjects with the greatest amount of protein excretion exhibited a significantly elevated risk of hyperkalemia. Baseline NSAID use was not found to be a significant pre dictor for hyperkalemia, but only $10.9 \%$ of the patients were taking NSAIDs at baseline (Table 1).

Table 4 presents results jointly relating the probability of hyperkalemia to the most recent recorded GFR, UP/Cr, diuretic use, and potassium level from the previous visit. Similar to the result observed for baseline GFR and potassium level, the most recent GFR, at both 30 $\mathrm{mL} / \mathrm{min} / 1.73 \mathrm{~m}^{2}$ or lower and between 30 and $40 \mathrm{~mL} / \mathrm{min} / 1.73 \mathrm{~m}^{2}$, was a significant predictor of a hyperkalemia event compared with the reference category of a GFR higher 
than $50 \mathrm{~mL} / \mathrm{min} / 1.73 \mathrm{~m}^{2}$. For most recent potassium measurement, the categories of higher than $5 \mathrm{mEq} / \mathrm{L}$ and between 4 and $5 \mathrm{mEq} / \mathrm{L}$ were a significant predictor of a hyperkalemia event compared with lower than $4 \mathrm{mEq} / \mathrm{L}$. In contrast to analyses of baseline covariates, the most recent UP/Cr was not a significant predictor of hyperkalemia after controlling for the most recent GFR. During the trial, diuretics were used for an average of $75 \%$ of follow-up visits. After controlling for the most recent GFR, use of diuretics was associated with a reduction in the probability of hyperkalemia by $59 \%(P=.006)$.

Figure 4 presents the distribution of levels of serum potassium at the time of the first occurrence of the potassium level-defined hyperkalemic events. Most hyperkalemic events fell into the category of 5.6 to $5.8 \mathrm{mEq} / \mathrm{L}$ for all of the 3 drug classes. No potassium level higher than $5.8 \mathrm{mEq} / \mathrm{L}$ was observed in the CCB group. Only 3 of the hyperkalemic events in the ACEI group were associated with a potassium level higher than $6.2 \mathrm{mEq} / \mathrm{L}$, and only 4 of the hyperkalemic events in the BB group were associated with a potassium level higher than $6.2 \mathrm{mEq} / \mathrm{L}$. Table 5 presents the number of patients with at least 1 serum potassium measurement higher than 5.5 or $6.0 \mathrm{mEq} / \mathrm{L}$, as well as the time from randomization until the first visit at which a serum potassium level was higher than $6.0 \mathrm{mEq} / \mathrm{L}$, stratified by GFR, BMI, and ACEI therapy. Of note, a serum potassium level higher than $6.0 \mathrm{mEq} / \mathrm{L}$ did not occur until more than 14 months of ACEI treatment in participants with a GFR higher than $40 \mathrm{~mL} / \mathrm{min} / 1.73 \mathrm{~m}^{2}$.

\section{COMMENT}

This study identifies readily measurable baseline and follow-up clinical variables that are associated with hyperkalemic events in nondiabetic African American patients with hypertensive CKD who are treated with commonly used classes of antihypertensive drug therapy. As expected, ACEI use was associated with significantly more episodes of hyperkalemia compared with CCBs and more events than BBs. Older age, baseline protein excretion, and both baseline and follow-up GFR and potassium levels were independent risk factors for development of hyperkalemia, regardless of antihypertensive drug class. Diuretic use was associated with a marked decrease in the risk of hyperkalemia. Importantly, a GFR higher than $40 \mathrm{~mL} / \mathrm{min} / 1.73 \mathrm{~m}^{2}$ was associated with a small risk of hyperkalemia, even in the presence of ACEI use. A BMI of 25 or lower was associated with significantly increased risk of hyperkalemia compared with a BMI higher than 25.

The association of hyperkalemia with lower GFR and renal dysfunction is consistent with the literature. ${ }^{18}$ In a population that included patients with diabetes and in which hyperkalemia was defined as a serum potassium level higher than $5.1 \mathrm{mEq} / \mathrm{L}$, risk factors for an event included a creatinine level higher than $1.5 \mathrm{mg} / \mathrm{dL}$ (to convert to micromoles per liter, multiply by 88.4). ${ }^{6}$ Also, during captopril treatment, transient elevations in potassium level higher than $6.0 \mathrm{mEq} / \mathrm{L}$ have been inversely related to GFR in markedly azotemic subjects. ${ }^{15}$ Our results extend these previous findings by demonstrating that this effect is independent of baseline randomized drug, age at randomization, sex, NSAID use, BMI, baseline UP/Cr, and baseline potassium level. In the patient population we studied, there is a clear increase in events in those with a GFR between 20 and $30 \mathrm{~mL} / \mathrm{min} / 1.73 \mathrm{~m}^{2}$ (ie, late stage 3 and stage 4 kidney disease). A limitation of the study is that the number of events in the group with a GFR lower than $20 \mathrm{~mL} / \mathrm{min} / 1.73 \mathrm{~m}^{2}$ is most likely an underestimation, as laboratory results were no longer collected from patients who received dialysis or underwent transplantation. A novel finding of this study is that baseline UP/Cr, a marker of renal dysfunction, is independently associated with hyperkalemic events.

There was more hyperkalemia in patients with a lower BMI. One possible explanation is less volume for drug distribution and thus higher concentration of the drug and more toxic 
adverse effects. However, since less precise measures of GFR may be affected by BMI, ${ }^{19}$ we also speculate that the iothalamate method may overestimate GFR in those with a BMI of 25 or lower. Hence the low BMI group might actually have a lower GFR than what was measured, which would result in detecting more hyperkalemia in this group.

Diuretic use was associated with a markedly reduced risk of hyperkalemia. Since lower GFR was associated with hyperkalemia, we considered the possibility that investigators used less diuretics in those with a lower GFR; we did not find evidence for this behavior. Consistent with previous reports in the literature, age was also an independent risk factor for hyperkalemia. ${ }^{6,18}$ The potential of ACEIs to increase occurrence of hyperkalemia in elderly patients was described over a decade ago. ${ }^{20}$ Use of NSAIDs has been associated with hyperkalemia, but we did not observe this association. ${ }^{21}$ However, only a small subset of patients were using NSAIDs because prior to randomization we eliminated patients with an inability to discontinue or a reported excessive NSAID use.

Several factors not measured in our study have been shown to increase the risk of hyperkalemia in various populations treated with ACEIs. Howes et $\mathrm{al}^{22}$ suggest that other predisposing factors include autonomic neuropathy and adrenal insufficiency. ${ }^{22}$ When captopril was administered to 23 patients by Atlas et al, ${ }^{5}$ those with high plasma renin activity experienced the greatest effects on aldosterone secretion and potassium balance, as well as the greatest reductions in BP. ${ }^{5}$

We recognize several limitations of our study. Keilani et al ${ }^{23}$ showed that in patients with mild CKD, low-dose $(1.25 \mathrm{mg} / \mathrm{d}$ by mouth) ramipril did not alter potassium level, but highdose $(10 \mathrm{mg} / \mathrm{d}$ by mouth) ramipril resulted in an increase in potassium level from 4.53 to $4.78 \mathrm{mEq} / \mathrm{L} .{ }^{23} \mathrm{We}$ did not find a significant difference in the rate of hyperkalemia between dose levels of ACEI, but the power to detect a difference was limited because more than two-thirds of our patients were receiving high-dose ACEI. Next, we recognize that our result may not be generalizable to all drugs in the classes we studied. Our study only included African Americans, and other ethnic groups might respond differently. Third, we recognize that patients may have been more carefully monitored in this clinical trial than in routine clinical care. Finally, in a general routine care setting, one would expect higher incidences of hyperkalemia than that reported in this study. The results of this study suggest, however, that the incidence of hyperkalemia in nondiabetic patients treated in a general medical care setting, even if higher than the incidence among those observed in this trial, would be low in patients with a GFR higher than $40 \mathrm{~mL} / \mathrm{min} / 1.73 \mathrm{~m}^{2}$. Our study has important clinical implications. If GFR at the time of initiation of therapy and during treatment is higher than $40 \mathrm{~mL} / \mathrm{min} / 1.73 \mathrm{~m}^{2}$, routine monitoring of serum potassium level is sufficient, even in those treated with ACEIs. Conversely, the results of this study would justify more frequent monitoring of serum potassium in the following subcategories: (1) patients with a GFR of 40 $\mathrm{mL} / \mathrm{min} / 1.73 \mathrm{~m}^{2}$ or lower who have a low BMI and are receiving treatment with an ACEI; (2) patients with a GFR of $30 \mathrm{~mL} / \mathrm{min} / 1.73 \mathrm{~m}^{2}$ or lower, irrespective of treatment, but especially with a BMI of 25 or lower; (3) older patients; (4) those with higher levels of microalbuminuria; and (5) those patients in whom a diuretic is not part of the medication regimen.

In conclusion, in the setting of nondiabetic, hypertensive CKD, the risk of hyperkalemia is inversely related to GFR and BMI, regardless of antihypertensive treatment. After initiation of antihypertensive therapy, the risk of hyperkalemia is greatest with ACEI use, intermediate with BB use, and lowest with CCB use. Including a diuretic as part of the medication regimen may markedly reduce the risk of hyperkalemia. 


\section{Acknowledgments}

Funding/Support: The AASK trial was sponsored by NIDDK grant 5U01 DK48689. The AASK trial received additional financial support from the Office of Research in Minority Health and drug donations from Pfizer Inc, AstraZeneca Pharmaceuticals, and King Pharmaceuticals.

\section{REFERENCES}

1. The GISEN Group (Gruppo Italiano di Studi Epidemiologici in Nefrologia). Randomised placebocontrolled trial of effect of ramipril on decline in glomerular filtration rate and risk of terminal renal failure in proteinuric, non-diabetic nephropathy. Lancet. 1997; 349(9069):1857-1863. [PubMed: 9217756]

2. Jafar TH, Schmid CH, Landa M, et al. Angiotensin-converting enzyme inhibitors and progression of nondiabetic renal disease: a meta-analysis of patient-level data. Ann Intern Med. 2001; 135(2):7387. [PubMed: 11453706]

3. Ruggenenti P, Perna A, Gherardi G, Gaspari F, Benini R, Remuzzi G. Renal function and requirement for dialysis in chronic nephropathy patients on long-term ramipril: REIN follow-up trial: Gruppo Italiano di Studi Epidemiologici in Nefrologia (GISEN): Ramipril Efficacy in Nephropathy. Lancet. 1998; 352(9136):1252-1256. [PubMed: 9788454]

4. Hou FF, Zhang X, Zhang GH, et al. Efficacy and safety of benazepril for advanced chronic renal insufficiency. N Engl J Med. 2006; 354(2):131-140. [PubMed: 16407508]

5. Atlas SA, Case DB, Sealey JE, Laragh JH, McKinstry DN. Interruption of the renin-angiotensin system in hypertensive patients by captopril induces sustained reduction in aldosterone secretion, potassium retention and natriuresis. Hypertension. 1979; 1(3):274-280. [PubMed: 399239]

6. Reardon LC, Macpherson DS. Hyperkalemia in outpatients using angiotensin-converting enzyme inhibitors: how much should we worry? Arch Intern Med. 1998; 158(1):26-32. [PubMed: 9437375]

7. Hannedouche T, Landais P, Goldfarb B, et al. Randomised controlled trial of enalapril and $\beta$ blockers in non-diabetic chronic renal failure. BMJ. 1994; 309(6958):833-837. [PubMed: 7950612]

8. Bakris GL, Siomos M, Richardson D, et al. VAL-K Study Group. ACE inhibition or angiotensin receptor blockade: impact on potassium in renal failure. Kidney Int. 2000; 58(5):2084-2092. [PubMed: 11044229]

9. Mangrum AJ, Bakris G. Angiotensin-converting enzyme inhibitors and angiotensin receptor blockers in chronic renal disease: safety issues. Semin Nephrol. 2004; 24(2):168-175. [PubMed: 15017529]

10. Brown MJ, Brown DC, Murphy MB. Hypokalemia from beta2-receptor stimulation by circulating epinephrine. N Engl J Med. 1983; 309(23):1414-1419. [PubMed: 6314140]

11. Vincent HH, Man in 't Veld AJ, Boomsma F, Derkx FH, Wenting GJ, Schalekamp MA. Cardioprotection by blockade of beta 2-adrenoceptors. Eur Heart J. 1983; 4(suppl D):109-115. [PubMed: 6137369]

12. Wright JT Jr, Bakris G, Greene T, et al. African American Study of Kidney Disease and Hypertension Study Group. Effect of blood pressure lowering and antihypertensive drug class on progression of hypertensive kidney disease: results from the AASK trial. JAMA. 2002; 288(19): 2421-2431. [PubMed: 12435255]

13. Agodoa LY, Appel L, Bakris GL, et al. African American Study of Kidney Disease and Hypertension (AASK) Study Group. Effect of ramipril vs amlodipine on renal outcomes in hypertensive nephrosclerosis: a randomized controlled trial. JAMA. 2001; 285(21):2719-2728. [PubMed: 11386927]

14. Reams GP, Bauer JH. Effect of enalapril in subjects with hypertension associated with moderate to severe renal dysfunction. Arch Intern Med. 1986; 146(11):2145-2148. [PubMed: 3022660]

15. Textor SC, Bravo EL, Fouad FM, Tarazi RC. Hyperkalemia in azotemic patients during angiotensin-converting enzyme inhibition and aldosterone reduction with captopril. Am J Med. 1982; 73(5):719-725. [PubMed: 6291388]

16. Suki WN. Disposition and regulation of body potassium: an overview. Am J Med Sci. 1976; 272(1):31-41. [PubMed: 134635] 
17. Singer, J.; Willet, J. Longitudinal Data Analysis: Modeling Change and Event Occurrence. Oxford University Press; New York, NY: 2003. Extending the discrete-time hazard model; p. 407-467.

18. Gennari FJ, Segal AS. Hyperkalemia: an adaptive response in chronic renal insufficiency. Kidney Int. 2002; 62(1):1-9. [PubMed: 12081558]

19. Wieczorowska-Tobis K, Niemir Z, Guzik P, Breborowicz A, Oreopoulos D. Difference in estimated GFR with two different formulas in elderly individuals. Int Urol Nephrol. 2006; 38(2): 381-385. [PubMed: 16868715]

20. Michelis MF. Hyperkalemia in the elderly. Am J Kidney Dis. 1990; 16(4):296-299. [PubMed: 2220773]

21. Murray MD, Brater DC. Renal toxicity of the nonsteroidal anti-inflammatory drugs. Annu Rev Pharmacol Toxicol. 1993; 33:435-465. [PubMed: 8494347]

22. Howes LG. Which drugs affect potassium. Drug Saf. 1995; 12(4):240-244. [PubMed: 7646822]

23. Keilani T, Danesh FR, Schlueter WA, Molteni A, Batlle D. A subdepressor low dose of ramipril lowers urinary protein excretion without increasing plasma potassium. Am J Kidney Dis. 1999; 33(3):450-457. [PubMed: 10070908]

24. Bakris GL, Weir MR. Angiotensin-converting enzyme inhibitor-associated elevations in serum creatinine: is this a cause for concern? Arch Intern Med. 2000; 160(5):685-693. [PubMed: 10724055] 


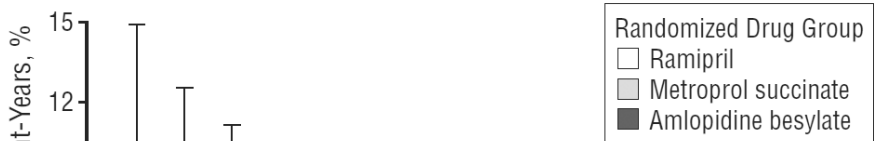

Figure 1.

Hyperkalemia event rate per 100 patient-years by randomized drug groups and baseline glomerular filtration rate (GFR). Error bars indicated $95 \%$ confidence intervals. 

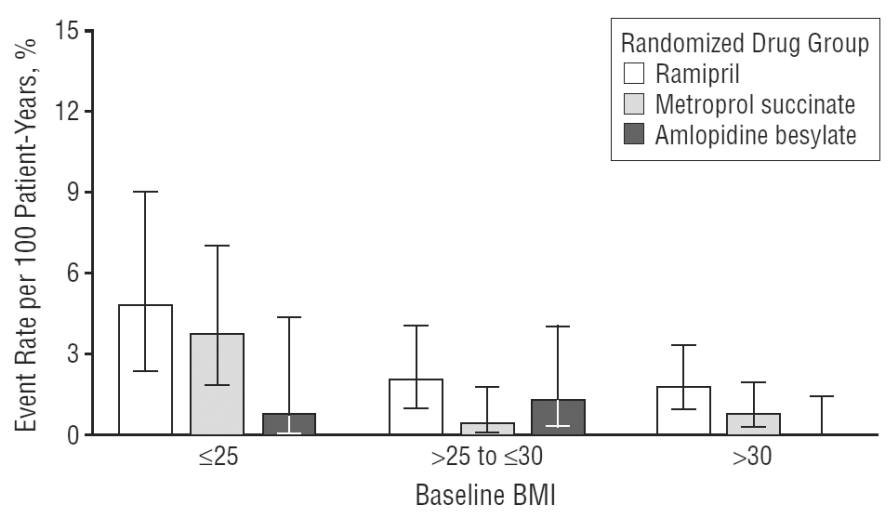

Figure 2.

Hyperkalemia even rate per 100 patient-years by randomized drug groups and baseline body mass index (BMI). Error bars indicated $95 \%$ confidence intervals. 


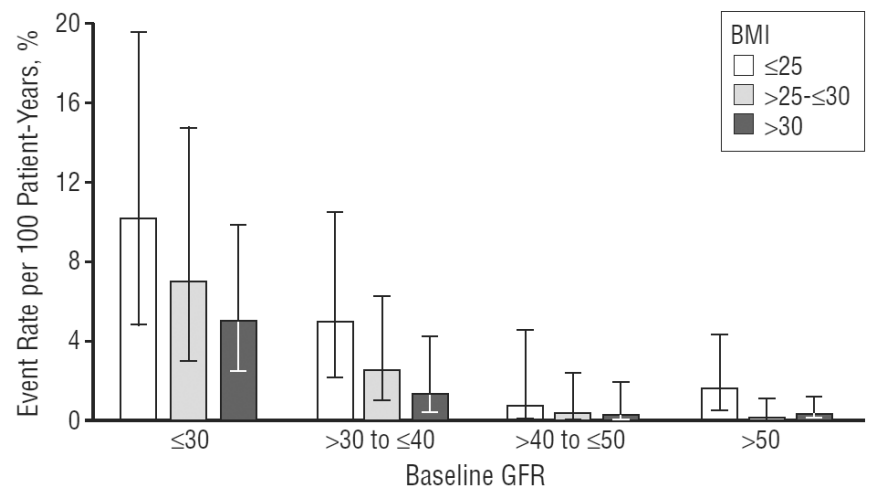

Figure 3.

Hyperkalemia event rate per 100 patient-years by glomerular filtration rate (GFR) and body mass index (BMI) subgroups. Error bars indicated $95 \%$ confidence intervals. 


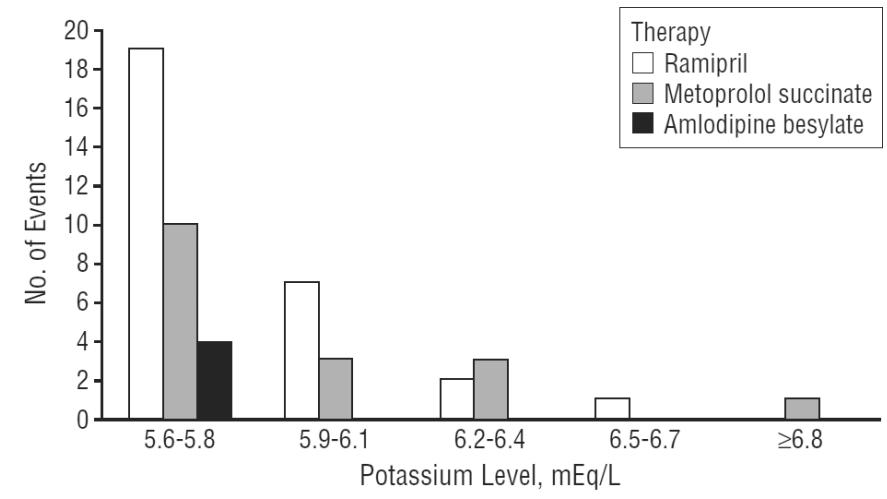

Figure 4.

Distribution of serum potassium levels at the occurrence of incident hyperkalemia events. To convert potassium to millimoles per liter, multiply by 1.0. ACEI indicates angiotensinconverting enzyme inhibitor; $\mathrm{BB}, \beta$-blocker; $\mathrm{CCB}$, dihydropyridine calcium channel blocker. 
Table 1

Baseline Demographic Characteristics ${ }^{a}$

\begin{tabular}{|c|c|c|c|c|c|}
\hline Variable & All (N=1053) & ACEI Group (n=417) & $\beta$-Blocker Group $(n=428)$ & $\begin{array}{r}\text { Calcium } \\
\text { Channel } \\
\text { Blocker Group } \\
(\mathbf{n}=\mathbf{2 0 8})\end{array}$ & $P$ Value \\
\hline Age at randomization, mean (SD), y & $54.6(10.7)$ & $54.3(10.9)$ & $55.0(10.3)$ & $54.3(10.8)$ & .62 \\
\hline Female sex, No. (\%) & $411(39.0)$ & $162(38.8)$ & $166(38.8)$ & $83(39.9)$ & .96 \\
\hline Body weight, mean (SD), kg & $89.4(20.6)$ & $89.8(20.0)$ & $90.1(21.2)$ & $87.1(20.6)$ & .20 \\
\hline BMI, mean (SD) & $30.5(6.57)$ & $30.7(6.33)$ & $30.7(6.87)$ & $29.9(6.37)$ & .26 \\
\hline Systolic BP, mean (SD), mm Hg & $150(23.6)$ & $151(22.6)$ & $150(23.6)$ & $150(25.4)$ & .82 \\
\hline Diastolic BP, mean (SD), mm Hg & $95.4(14.1)$ & $96.0(14.4)$ & $94.8(13.8)$ & $95.6(14.2)$ & .49 \\
\hline MAP, mean (SD), mm Hg & $114(15.9)$ & $114(15.6)$ & $113(15.7)$ & $114(16.8)$ & .60 \\
\hline $\begin{array}{l}\text { Baseline GFR, mean (SD), } \mathrm{mL} / \mathrm{min} / \\
1.73 \mathrm{~m}^{2}\end{array}$ & $46.6(13.6)$ & $46.3(13.5)$ & $46.7(13.9)$ & $46.8(13.1)$ & .87 \\
\hline $\begin{array}{l}\text { Male serum creatinine, mean (SD), mg/ } \\
\text { dL }\end{array}$ & $2.18(0.76)$ & $2.18(0.74)$ & $2.13(0.75)$ & $2.28(0.82)$ & .18 \\
\hline $\begin{array}{l}\text { Female serum creatinine, mean (SD), } \\
\mathrm{mg} / \mathrm{dL}\end{array}$ & $1.77(0.57)$ & $1.76(0.59)$ & $1.80(0.55)$ & $1.73(0.56)$ & .60 \\
\hline Male UP/Cr, mean (SD) & $0.31(0.50)$ & $0.33(0.51)$ & $0.31(0.50)$ & $0.29(0.46)$ & .77 \\
\hline Female UP/Cr, mean (SD) & $0.33(0.54)$ & $0.33(0.53)$ & $0.35(0.54)$ & $0.31(0.56)$ & .87 \\
\hline Male urine protein, mean (SD), g/d & $0.59(1.03)$ & $0.60(0.99)$ & $0.60(1.09)$ & $0.56(0.99)$ & .92 \\
\hline Female urine protein, mean (SD), g/d & $0.42(0.74)$ & $0.41(0.76)$ & $0.44(0.72)$ & $0.39(0.74)$ & .87 \\
\hline $\mathrm{UP} / \mathrm{Cr} \geq 22$, No. (\%) & $333(31.7)$ & $134(32.4)$ & $135(31.5)$ & $64(30.9)$ & .92 \\
\hline Baseline ACEIs, No. (\%) & $402(39.2)$ & $169(41.5)$ & $147(35.3)$ & $86(42.8)$ & .09 \\
\hline Baseline diuretics, No. (\%) & $659(64.3)$ & $264(64.9)$ & $261(62.6)$ & $134(66.7)$ & .58 \\
\hline Baseline NSAID use, No. (\%) & $115(10.9)$ & $45(10.8)$ & $52(12.1)$ & $18(8.7)$ & .41 \\
\hline Baseline potassium, mean $(\mathrm{SD}), \mathrm{mEq} / \mathrm{L}$ & $4.24(0.59)$ & $4.23(0.56)$ & $4.22(0.57)$ & $4.30(0.69)$ & .23 \\
\hline Baseline glucose, mean (SD), mg/dL & $95.2(18.3)$ & $94.7(17.8)$ & $96.0(18.5)$ & $94.5(19.0)$ & .51 \\
\hline
\end{tabular}

Abbreviations: ACEI, angiotensin converting enzyme inhibitor; BMI, body mass index (calculated as weight in kilograms divided by height in meters squared); BP, blood pressure; GFR, glomerular filtration rate; MAP, mean arterial BP; NSAID, nonsteroidal anti-inflammatory drug; UP/ $\mathrm{Cr}$, urinary protein to creatinine ratio.

SI conversion factors: To convert creatinine to micromoles per liter, multiply by 88.4 ; glucose to millimoles per liter, multiply by 0.0555 ; potassium to millimoles per liter, multiply by 1.0 .

${ }^{a}$ Comparing baseline factors between randomized drug groups. 
Table 2

Number of Patients With Hyperkalemic Events $(n=51)$ by Baseline Factors

\begin{tabular}{|c|c|c|c|}
\hline Variable & No. of Patients & No. of Events (\%) & Event Rate per 100 Patient-Years (95\% CI) \\
\hline \multicolumn{4}{|c|}{ Baseline GFR, $\mathrm{mL} / \mathrm{min} / 1.73 \mathrm{~m}^{2}$} \\
\hline $\mathfrak{3 0}$ & 165 & $25(15.2)$ & $6.87(4.44-10.14)$ \\
\hline$>30$ to $\leq 40$ & 193 & $15(7.8)$ & $2.75(1.54-4.53)$ \\
\hline$>40$ to 50 & 214 & $3(1.4)$ & $0.45(0.09-1.32)$ \\
\hline$>50$ & 481 & $8(1.7)$ & $0.52(0.22-1.02)$ \\
\hline \multicolumn{4}{|l|}{ Baseline BMI } \\
\hline$\underline{25}$ & 214 & $21(9.8)$ & $3.53(2.18-5.39)$ \\
\hline$>25$ to $\leq 30$ & 349 & $14(4.0)$ & $1.33(0.72-2.23)$ \\
\hline$>30$ & 490 & $16(3.3)$ & $1.09(0.62-1.77)$ \\
\hline \multicolumn{4}{|l|}{ Randomized drug } \\
\hline Ramipril & 417 & $30(7.2)$ & $2.45(1.65-3.50)$ \\
\hline Metoprolol succinate & 428 & $17(4.0)$ & $1.33(0.77-2.13)$ \\
\hline Amlodipine besylate & 208 & $4(1.9)$ & $0.66(0.18-1.68)$ \\
\hline \multicolumn{4}{|l|}{ Baseline NSAID use } \\
\hline No & 938 & $45(4.8)$ & $1.63(1.19-2.19)$ \\
\hline Yes & 115 & $6(5.2)$ & $1.68(0.61-3.65)$ \\
\hline \multicolumn{4}{|l|}{ Baseline UP/Cr } \\
\hline$\unlhd 0.08$ & 528 & $13(2.5)$ & $0.77(0.41-1.32)$ \\
\hline$>0.08-\$ 0.22$ & 188 & $12(6.4)$ & $2.19(1.13-3.83)$ \\
\hline$>0.22-\unlhd 0.66$ & 163 & $7(4.3)$ & $1.51(0.61-3.11)$ \\
\hline$>0.66$ & 170 & $19(11.2)$ & $4.66(2.81-7.28)$ \\
\hline \multicolumn{4}{|c|}{ Baseline potassium, $\mathrm{mEq} / \mathrm{L}$} \\
\hline$<4$ & 339 & $1(0.3)$ & $0.10(0.002-0.53)$ \\
\hline $4-5$ & 620 & $33(5.3)$ & $1.83(1.26-2.57)$ \\
\hline$>5$ & 94 & $17(18.1)$ & $6.56(3.82-10.51)$ \\
\hline \multicolumn{4}{|l|}{ Baseline glucose, $\mathrm{mg} / \mathrm{dL}$} \\
\hline$<100$ & 734 & $42(5.7)$ & $1.98(1.42-2.67)$ \\
\hline $100-115$ & 210 & $8(3.8)$ & $1.24(0.53-2.44)$ \\
\hline$>115$ & 109 & $1(0.9)$ & $0.29(0.01-1.61)$ \\
\hline
\end{tabular}

Abbreviations: BMI, body mass index (calculated as weight in kilograms divided by height in meters squared); CI, confidence interval; GFR, glomerular filtration rate; NSAID, nonsteroidal anti-inflammatory drug; UP/Cr, urinary protein to creatinine ratio.

SI conversion factors: To convert glucose to millimoles per liter, multiply by 0.0555 ; potassium to millimoles per liter, multiply by 1.0 . 
Table 3

Association of Risk of Hyperkalemia With Baseline Factors

\begin{tabular}{|c|c|c|c|c|c|c|}
\hline \multirow[b]{2}{*}{ Variable } & \multicolumn{2}{|c|}{$\underline{\text { Randomized Group Comparisons }^{a}}$} & \multicolumn{2}{|c|}{ Univariate Analysis ${ }^{b}$} & \multicolumn{2}{|c|}{ Multivariable Analyses $c$} \\
\hline & HR $(95 \% \mathrm{CI})$ & $P$ Value & HR $(95 \%$ CI) & $P$ Value & HR $(95 \%$ CI) & $P$ Value \\
\hline $\mathrm{BB}$ vs $\mathrm{CCB}$ & $2.07(0.70-6.16)$ & .19 & NA & NA & $2.45(0.79-7.65)$ & .12 \\
\hline ACEI vs CCB & $3.84(1.35-10.89)$ & .01 & NA & NA & $7.00(2.29-21.39)$ & $<.001$ \\
\hline ACEI vs BB & $1.85(1.02-3.36)$ & .04 & NA & NA & $2.85(1.50-5.42)$ & .001 \\
\hline Low vs usual BP & $1.10(0.64-1.91)$ & .72 & NA & NA & $1.28(0.72-2.29)$ & .40 \\
\hline Age at randomization, $10 \mathrm{y}$ & NA & NA & $1.26(0.95-1.67)$ & .10 & $1.40(1.05-1.88)$ & .02 \\
\hline Female sex & NA & NA & $0.85(0.48-1.53)$ & .60 & $0.52(0.28-0.98)$ & .04 \\
\hline Baseline NSAID use & NA & NA & $1.02(0.43-2.38)$ & .97 & $0.93(0.38-2.32)$ & .88 \\
\hline $\begin{array}{l}\text { Mean baseline GFR } \leq 30 \text { vs }>50 \\
\mathrm{~mL} / \mathrm{min} / 1.73 \mathrm{~m}^{2}\end{array}$ & NA & NA & $13.09(5.83-29.39)$ & $<.001$ & $6.81(2.67-17.35)$ & $<.001$ \\
\hline $\begin{array}{l}\text { Mean baseline GFR } 31-40 \mathrm{vs} \\
>50 \mathrm{~mL} / \mathrm{min} / 1.73 \mathrm{~m}^{2}\end{array}$ & NA & NA & $5.44(2.30-12.85)$ & $<.001$ & $3.61(1.42-9.18)$ & .007 \\
\hline $\begin{array}{l}\text { Mean baseline GFR } 41-50 \mathrm{vs} \\
>50 \mathrm{~mL} / \mathrm{min} / 1.73 \mathrm{~m}^{2}\end{array}$ & NA & NA & $0.85(0.23-3.22)$ & .82 & $0.61(0.16-2.35)$ & .47 \\
\hline BMI $\_5$ vs $>25$ to $\_30 \mathrm{~kg} / \mathrm{m}^{2}$ & NA & NA & $2.68(1.36-5.29)$ & .004 & $1.92(0.95-3.89)$ & .07 \\
\hline BMI $>30$ vs $>25$ to $<30 \mathrm{~kg} / \mathrm{m}^{2}$ & NA & NA & $0.77(0.38-1.59)$ & .48 & $0.82(0.39-1.74)$ & .61 \\
\hline $\begin{array}{l}\text { Baseline UP/Cr 0.08-0.22 vs } \\
\text { \).08 }\end{array}$ & NA & NA & $2.70(1.23-5.93)$ & .01 & $2.27(0.96-5.36)$ & .06 \\
\hline $\begin{array}{l}\text { Baseline UP/Cr } 0.22-0.66 \text { vs } \\
₫ 1.08\end{array}$ & NA & NA & $1.83(0.73-4.60)$ & .20 & $1.15(0.42-3.14)$ & .78 \\
\hline Baseline $\mathrm{UP} / \mathrm{Cr}>0.66$ vs $₫) .08$ & NA & NA & $5.86(2.88-11.92)$ & $<.001$ & $3.63(1.58-8.34)$ & .002 \\
\hline $\begin{array}{l}\text { Baseline glucose level 100-115 } \\
\text { vs }<100 \mathrm{mg} / \mathrm{dL}\end{array}$ & NA & NA & $0.63(0.30-1.35)$ & .24 & $1.08(0.50-2.36)$ & .84 \\
\hline $\begin{array}{l}\text { Baseline glucose level }>115 \text { vs } \\
<100 \mathrm{mg} / \mathrm{dL}\end{array}$ & NA & NA & $0.14(0.02-1.04)$ & .05 & $0.22(0.03-1.59)$ & .13 \\
\hline $\begin{array}{l}\text { Baseline potassium level } 4-5 \\
\text { vs }<4 \mathrm{mEq} / \mathrm{L}\end{array}$ & NA & NA & $18.48(2.53-135.10)$ & .004 & $14.81(2.01-109.10)$ & .008 \\
\hline $\begin{array}{l}\text { Baseline potassium level }>5 \text { vs } \\
<4 \mathrm{mEq} / \mathrm{L}\end{array}$ & NA & NA & $85.54(11.36-644.20)$ & $<.001$ & $53.72(6.97-414.20)$ & $<.001$ \\
\hline
\end{tabular}

Abbreviations: ACEI, angiotensin-converting enzyme inhibitor; BB, $\beta$-blocker; BMI, body mass index (calculated as weight in kilograms divided by height in meters squared); BP, blood pressure; CCB, calcium channel blocker; CI, confidence interval; GFR, glomerular filtration rate; HR, hazard ratio; NA, not applicable; NSAID, nonsteroidal anti-inflammatory drug; UP/Cr, urinary protein to creatinine ratio.

SI conversion factors: To convert glucose to millimoles per liter, multiply by 0.0555 ; potassium to millimoles per liter, multiply by 1.0 .

a Hazard ratios corresponding to comparisons of randomized treatment assignments, without adjustment for other baseline factors.

${ }^{b}$ Controlling only for randomized groups.

${ }^{c}$ Hazard ratio associated with each factor adjusted for all other factors included in the model. 
Table 4

Association of Risk of Hyperkalemia With Time-Dependent Factors in Multivariable Analysis ${ }^{a}$

\begin{tabular}{|c|c|c|}
\hline Variable & Hazard Ratio (95\% Confidence Interval) & $P$ Value \\
\hline Follow-up diuretic use & $0.41(0.22-0.78)$ & .006 \\
\hline Follow-up GFR $\_30 \mathrm{vs}>50 \mathrm{~mL} / \mathrm{min} / 1.73 \mathrm{~m}^{2}$ & $9.07(3.18-25.88)$ & $<.001$ \\
\hline Follow-up GFR $>30$ to $\leq 40 \mathrm{vs}>50 \mathrm{~mL} / \mathrm{min} / 1.73 \mathrm{~m}^{2}$ & $3.67(1.21-11.15)$ & .02 \\
\hline Follow-up GFR $>40$ to $\leq 50 \mathrm{vs}>50 \mathrm{~mL} / \mathrm{min} / 1.73 \mathrm{~m}^{2}$ & $1.98(0.59-6.61)$ & .27 \\
\hline Follow-up UP/Cr $>0.08$ to $\unlhd) .22$ vs $\unlhd) .08$ & $2.01(0.92-4.39)$ & .08 \\
\hline Follow-up UP/Cr $>0.22$ to $\triangleleft 9.66$ vs $\unlhd 0.08$ & $1.50(0.62-3.63)$ & .37 \\
\hline Follow-up UP/Cr $>0.66$ vs $\unlhd) .08$ & $1.84(0.78-4.30)$ & .16 \\
\hline Follow-up potassium level $4-5$ vs $<4 \mathrm{mEq} / \mathrm{L}$ & $7.25(1.72-30.58)$ & .007 \\
\hline Follow-up potassium level $>5 \mathrm{vs}<4 \mathrm{mEq} / \mathrm{L}$ & $30.83(6.89-138.0)$ & $<.001$ \\
\hline
\end{tabular}

Abbreviations: GFR, glomerular filtration rate; UP/Cr, urinary protein to creatinine ratio.

SI conversion factor: To convert potassium to millimoles per liter, multiply by 1.0.

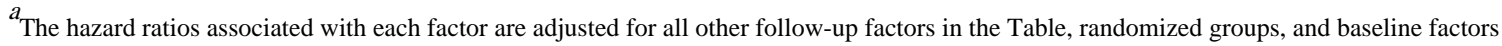
including age, sex, nonsteroidal anti-inflammatory drug use, body mass index, and glucose level. 
Table 5

Time From Randomization Until First Serum Potassium Measurement Higher Than $6.0 \mathrm{mEq} / \mathrm{L}$, Stratified by GFR, BMI, and ACEI Therapy

\begin{tabular}{|c|c|c|c|c|c|}
\hline Variable & No. of Patients & $\begin{array}{r}\text { No. of Patients } \\
\text { With at Least } 1 \\
\text { Follow-up Serum } \\
\text { Potassium } \\
\text { Measurement }\end{array}$ & $\begin{array}{r}\text { No. of Patients } \\
\text { With at Least } 1 \\
\text { Serum Potassium } \\
\text { Measurement } \\
>5.5 \mathrm{mEq} / \mathrm{L}\end{array}$ & $\begin{array}{r}\text { No. of Patients } \\
\text { With at Least } 1 \\
\text { Serum Potassium } \\
\text { Measurement } \\
>6.0 \mathrm{mEq} / \mathrm{L}\end{array}$ & $\begin{array}{r}\text { Time (mo) From } \\
\text { Randomization } \\
\text { Until First } \\
\text { Recorded Serum } \\
\text { Potassium } \\
\text { Measurement }>6.0 \\
\mathrm{mEq} / \mathrm{L}\end{array}$ \\
\hline All patients & 1094 & 1053 & 50 & 15 & 5.16 \\
\hline All ACEI-treated patients & 436 & 417 & 29 & 8 & 5.16 \\
\hline $\begin{array}{l}\text { All ACEI-treated patients with a } \\
\text { GFR } \leq 40\end{array}$ & 148 & 139 & 22 & 7 & 5.16 \\
\hline $\begin{array}{l}\text { All ACEI-treated patients with a } \\
\text { GFR }>40\end{array}$ & 288 & 278 & 7 & 1 & 14.36 \\
\hline $\begin{array}{l}\text { All ACEI-treated patients with a } \\
\text { BMI } 25\end{array}$ & 80 & 75 & 10 & 4 & 6.64 \\
\hline $\begin{array}{l}\text { All ACEI-treated patients with a } \\
\text { BMI > } 25\end{array}$ & 356 & 342 & 19 & 4 & 5.16 \\
\hline
\end{tabular}

Abbreviations: ACEI, angiotensin-converting enzyme inhibitor; BMI, body mass index (calculated as weight in kilograms divided by height in meters squared); GFR, glomerular filtration rate.

SI conversion factor: To convert potassium to millimoles per liter, multiply by 1.0. 